\title{
Effect of Repeated Simulated Disinfections by Microwave Energy on the Complete Denture Base Adaptation
}

\author{
Rafael L.X. Consani ${ }^{1, *}$, Rose Y. Iwasaki ${ }^{2}$, Marcelo F. Mesquita ${ }^{3}$, Wilson B. Mendes ${ }^{4}$ and \\ Simonides Consani ${ }^{5}$
}

${ }^{I}$ Department of Prosthodontics and Periodontics, Piracicaba Dentistry School, State University of Campinas, Piraci-
caba, SP, Brazil; ${ }^{2}$ Under Graduate Student, Piracicaba Dentistry School, State University of Campinas, Piracicaba, SP,
Brazil; ${ }^{3}$ Department of Prosthodontics and Periodontics, Piracicaba Dentistry School, State University of Campinas,
Piracicaba, SP, Brazil; ${ }^{4}$ Department of Clinics, Dentistry School of the Itauna University, Itauna, MG, Brazil and
${ }^{5}$ Department of Restorative Dentistry, Piracicaba Dentistry School, State University of Campinas, Piracicaba, SP, Brazil

\begin{abstract}
This study evaluated the effect of repeated microwave disinfections on the adaptation of the maxillar denture base using 2 different flask closure methods. Twenty stone cast-wax base sets were prepared for flasking by traditional cramp or RS system methods. Five bases for each method were submitted to 5 repeated simulated disinfections in a microwave oven with $650 \mathrm{~W}$ for 3 minutes. Control bases were not disinfected. Three transverse cuts were made through each stone cast-resin base set, corresponding to canine, first molar, and posterior region. Measurements were made using an optical micrometer at 5 points for each cut to determine base adaptation: left and right marginal limits of the flanges, left and right ridge crests, and midline. Results for base adaptation performed by the flask closure methods were: traditional cramp (non-disinfected $=0.21 \pm 0.05 \mathrm{~mm}$ and disinfected $=0.22 \pm 0.05 \mathrm{~mm}$ ), and RS system (non-disinfected $=0.16$ \pm 0.05 and disinfected $=0.17 \pm 0.04 \mathrm{~mm})$. Collected data were submitted to ANOVA and Tukey test $(\alpha=.05)$. Repeated simulated disinfections by microwave energy did not cause deleterious effect on the base adaptation, when the traditional cramp and RS system flask closure methods were compared.
\end{abstract}

Key Words: Denture base, adaptation, microwave disinfection, flask closure.

\section{INTRODUCTION}

In addition to the changes occurred due to several variables, such as linear shrinkage of the acrylic resins [1], denture processing [2,3], commercial types of acrylic resins [4], flask closure methods [5], and post-pressing times [6], treatments for denture disinfection performed by chemical [7] and microwave irradiation methods can also promote linear dimensional changes [8-11].

Prosthesis can be contaminated by microorganisms during manufacture or manipulation, or by the patients. As an effort to eliminate or decrease cross-contamination, chemical solutions should be used for prosthesis disinfection. Materials sent from dental clinics to prosthetic laboratories were contaminated by bacteria [12], and sterile prostheses could be contaminated during polishing or by microorganisms transferred from other prostheses during laboratory practice [13-15].

Glutaraldehyde, sodium hypochlorite, iodoform, or chlorine dioxide had been suggested for prosthesis chemical disinfection to avoid cross-contamination, [16-21]; however, this method shows disadvantages such as prosthesis staining and oral tissue reactions [22, 23].

Microwave energy was used for polymerization of the thermally activated acrylic resins [24], and microwave irra-

*Address correspondence to this author at the Faculdade de Odontologia de Piracicaba, UNICAMP, Av. Limeira, 901, 13414-903 - Piracicaba, SP, Brazil; E-mail: rconsani@fop.unicamp.br diation of resilient materials and acrylic resins in a microwave oven effectively sterilized specimens contaminated by fungi [22], Candida albicans or Staphylococcus aureus [23]. Microwave energy has been recommended for prosthesis disinfection [25] when the probability of the denture base being contaminated internally and externally is considered [21].

Earlier study showed comparison between chemical disinfection with glutaraldehyde solution and by microwave energy (500W intensity for 3 or 15 minutes) on hardness, dimensional changes, and flexural strength of the acrylic resin. The findings showed that these properties were not altered by either disinfection procedures [25].

Some studies have identified whether microwave disinfection promotes changes in the complete denture base adaptation $[8-11,26]$. Although a soft tissue displacement of only $0.25 \mathrm{~mm}$ would be necessary to allow almost complete seating of the denture on the oral tissue [27], disinfection procedures should not cause dimensional changes or distortion in the denture base, since these factors can compromise the retention and stability of the dentures.

The purpose of this study was to evaluate and compare the effect of repeated simulated microwave disinfections on the adaptation of the maxillary complete denture achieved when bases were prepared using the traditional cramp flask closure (TFC) and Restriction System flask closure (RSFC) methods [28]. The research hypothesis tested in this in vitro study was that the denture base adaptation prepared using the 
TFC and RSFC methods could be adversely affected by repeated simulated disinfections by microwaves energy.

\section{MATERIAL AND METHODS}

\section{Material}

An acrylic resin (Batch \# 009-04, Classico; Classico Dental Products, Sao Paulo, SP, Brazil) was used to fabricate maxillary complete denture bases. The manufacturer purports that Classico is a conventional acrylic resin based on a polymethyl methacrylate copolymer with heat activation (Powder: prepolymerized spheres of polymethyl methacrylate and benzoyl peroxide as initiator. Liquid: unpolymerized copolymer of methyl methacrylate and ethylacrylate, and hydroquinone as inhibitor).

\section{Methods}

Impressions were made from a metal die simulating an edentulous maxillary arch with vinylpolysiloxane duplicating material (Batch \# 37608, Elite Double 8; Zhermack, Rovigo, Italy), and twenty correspondent stone casts were poured in type III dental stone (batch \# 00709, Herodent; Vigodent, Rio de Janeiro, RJ, Brazil). A 2-mm thick wax base (Batch \# 195-05, Epoxiglass; Epoxiglass Chemical Products, Diadema, SP, Brazil) was made by the same technician for each cast stone and measured with a caliper for standardization purposes (Golgran; Colgran Dental Products, Sao Paulo, SP, Brazil). The stone cast-wax base sets were codified with numbers to blind the examiner, and randomly divided into the following groups $(\mathrm{n}=5)$ : (1) bases made for the traditional cramp flask closure method (TFC) and nondisinfected (ND); (2) bases made for the TFC method and submitted to repeated simulated disinfections by microwave (RSD); (3) bases made for the RS system flask closure method (RSFC) and ND; and (3) bases made for the RSFC method submitted to RSD.

The stone cast-wax pattern sets were flasked in the lower part of traditional brass flasks (Safrany; J. Safrany Mettalurgy, Sao Paulo, SP, Brazil) with type II dental plaster (Batch \# 2410, Star; Chaves, Fortaleza, CE, Brazil, and type III dental stone (Herodent; Vigodent) was used in the upper portion. After 1 hour, the flasks were placed in boiling water to soften and remove the wax pattern. After removal, the stone was cleaned with boiling water and liquid detergent solution (Limpol; Bombril-Cirio, Sao Paulo, SP, Brazil). Sodium alginate (Batch \# 998010, Isolak; Classico Dental Products) was used as a mold separator.

The acrylic resin (Classico; Classico Dental Products) was prepared using a solution with a ratio of $35.5 \mathrm{~g}$ powder to $15 \mathrm{~mL}$ liquid, according to the manufacturer's instructions. In the TFC groups (ND and RSD), the flasks were placed in traditional cramps after final pressing in a hydraulic press (Linea H; Linea, Sao Paulo, SP, Brazil) under a load of $1,250 \mathrm{kgf}$ for 5 minutes. In the RSFC groups (ND and RSD), trial packing was similar to the TFC method; however, during final pressing the flasks were positioned in the RSFC system [28]. During flask closure, the screws of the lower plate were fitted into the holes of the upper plate and, after applying flask pressure, the screw nuts were tightened to the screws. This procedure maintained constant flask closing pressure before release of the hydraulic press.
The flasks were immersed in water at room temperature, and the polymerizing unit (Termotron; Termotron Laboratory Products, Piracicaba, SP, Brazil) was programmed to raise the temperature to $74^{\circ} \mathrm{C}$ for 1 hour. This temperature was then maintained for 8 hours. Flask cooling was performed at room temperature before the acrylic resin bases were deflasked, and finished with abrasive stones (AcryPoint; Shofu Dental Corp, Menlo Park, Calf). Resin bases made by TFC-SD and RSFC-SD methods $(n=5)$ were immersed individually in $150 \mathrm{~mL}$ of distilled water in a glass container, and submitted to repeated simulated disinfections in a domestic microwave oven (Continental; Continental Domestic Lines, Manaus, AM, Brazil), calibrated to $650 \mathrm{~W}$ for 3 minutes [23]. Five simulated disinfections, one by day, were made in each denture base. During the interval between disinfection procedures, the denture base was stored in a stove (Orion 502; Fanem, Sao Paulo, SP, Brazil), immersed in distilled water at $37^{\circ} \mathrm{C}$. Control bases prepared by the TFC-ND and RSFC-ND methods ( $\mathrm{n}=5$ ) were not disinfected. All bases submitted to the ND and RSD treatments were attached to the corresponding stone casts with adhesive ( $\mathrm{Su}$ per Bonder; Loctite, Sao Paulo, SP, Brazil) placed on the ridge crest of the stone cast.

The base-cast sets were transversally sectioned in a sawing device (Precat Manufacturing Co., Piracicaba, SP, Brazil) into 3 sections: canine, first molar, and posterior palate (Fig. 1). The gap between the acrylic resin base and stone cast was measured in the 3 sections at 5 points, corresponding to the right and left residual ridge crests, the midline, and the right and left marginal limits of the flanges. Arithmetical mean of the reference points of each section was considered as the adaptation value for each section [27] (Fig. 2). An optical micrometer (STM; Olympus Optical Co, Tokyo, Japan)

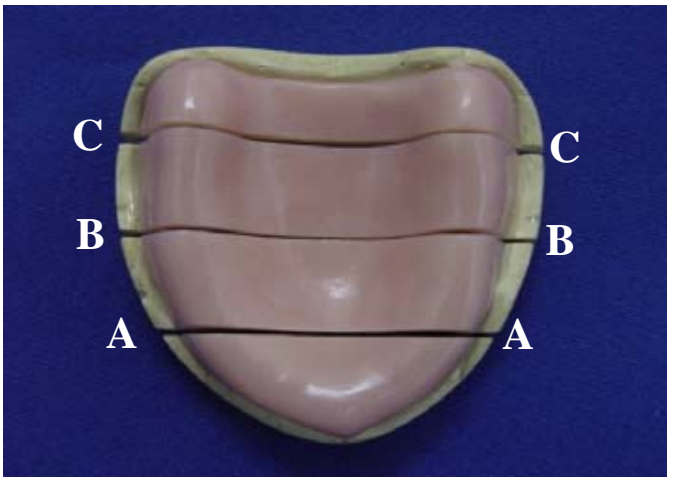

Fig. (1). Transversal cuts in base-cast set: canine (A), first molar (B), and posterior palate (C).

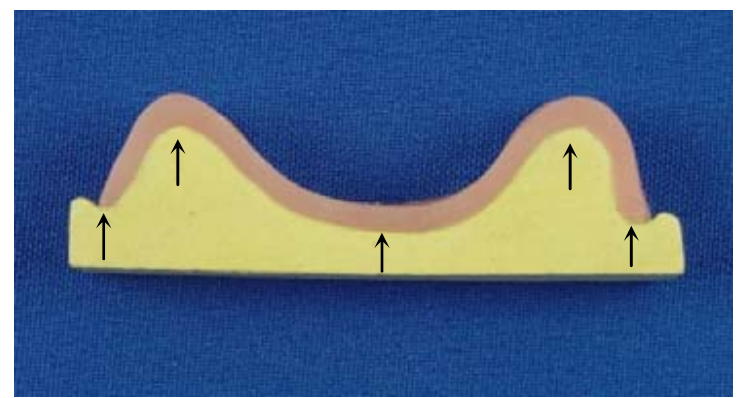

Fig. (2). Measurement points corresponding to right and left residual ridge crests, midline, and right and left marginal limits of flanges (arrows). 
Table 1. Results of 3-Way ANOVA

\begin{tabular}{|c|c|c|c|c|c|}
\hline Variation Cause & $\boldsymbol{d f}$ & Sum of Squares & Mean Square & F & 83.857 \\
\hline \hline Closure & 1 & 0.039 & 0.039 & 3.756 & 0.001 \\
\hline Disinfection & 1 & 0.001 & 0.001 & 0.000 & .005 \\
\hline Closure x Disinfection & 1 & 0.000 & 0.000 & 156.113 \\
\hline Error A & 16 & 0.013 & 2.561 & 0.508 \\
\hline Repetition & 19 & 0.043 & 0.074 & .001 \\
\hline Region & 2 & 0.148 & 0.001 & .085 \\
\hline Closure x Region & 2 & 0.002 & 0.000 & .609 \\
\hline Disinfection x Region & 2 & 0.000 & 0.000 & 0.327 \\
\hline Clos. x Disin. x Reg. & 32 & 0.000 & 0.000 & .727 \\
\hline Error (B) & 59 & 0.005 & & \\
\hline Total & 0.171 & & \\
\hline
\end{tabular}

General mean $=0.19 ;$ variation coefficient $(A)=9.374 \%$; variation coefficient $(B)=7.049 \%$.

with an accuracy of $0.0005 \mathrm{~mm}$ was used for measurement purposes.

Data were submitted to 3-way analysis of variance (ANOVA), considering 3 factors (flask closure method, repeated simulated disinfection, and region) and their interactions. The split-plot design was used, supported by repeated measurements made from the same experimental group at different base-cast set cuts. Differences were submitted to multiple comparison testing (Tukey HSD test at $\alpha=.05$ ).

\section{RESULTS}

Three-way ANOVA (Table 1) revealed significant difference in the denture adaptation for the variables flask closure $(P<.001)$ and region $(P<.001)$. The interactions between the factors were not significant.

Table 2 presents mean adaptation values for denture base obtained with TFC and RSFC methods. Denture base fit values obtained for the RSFC method (ND $=0.16 \pm 0.05 \mathrm{~mm}$, and $\mathrm{RSD}=0.17 \pm 0.04 \mathrm{~mm})$ were significantly lower $(p<.05)$ than those obtained for the TFC method (ND $=0.21 \pm$ $0.05 \mathrm{~mm}$ and $\mathrm{RSD}=0.22 \pm 0.05 \mathrm{~mm})$. RSD had no significant effect $(p>.05)$ on the base adaptation when compared with the ND treatment.

Table 3 shows statistically significant difference $(p<.05)$ in the adaptation among the regions for TFC method, when the denture bases were submitted to ND (canine: $0.15 \pm$ $0.01 \mathrm{~mm}$, first molar: $0.20 \pm 0.02 \mathrm{~mm}$, and posterior palate: $0.29 \pm 0.01 \mathrm{~mm}$ ) or RSD (canine: $0.16 \pm 0.01 \mathrm{~mm}$, first molar: $0.21 \pm 0.01 \mathrm{~mm}$, and posterior palate: $0.30 \pm 0.01 \mathrm{~mm}$ ) treatments. The best fit occurred in canine region, the worst was in posterior palate, and intermediary values were shown in first molar region. When the regions were compared individually, there was not statistically significant difference between ND and RSD treatments $(p>.05)$.
Table 2. Means Values (mm) for Denture Base Adaptation Concerning to Flask Closure Method and Microwave Disinfection (Standard Deviations are Given in Parenthesis)

\begin{tabular}{|c|c|c|}
\hline \multirow{2}{*}{ Flask Closure } & \multicolumn{2}{|c|}{ Microwave Disinfection } \\
\cline { 2 - 3 } & Non-Disinfected & Simulated \\
\hline \hline TFC & $0.21(0.05)$ a A & $0.22(0.05)$ a A \\
\hline RSFC & $0.16(0.05)$ b A & $0.17(0.04)$ b A \\
\hline
\end{tabular}

Means values followed by different lower case letters in each column and upper case letters in each row differ significantly at $5 \%$.

Table 3. Means Values $(\mathrm{mm})$ for Denture Base Adaptation Concerning to Cut Region and Microwave Disinfection for TFC Method (Standard Deviations are Given in Parenthesis)

\begin{tabular}{|c|c|c|}
\hline \multirow{2}{*}{ Region } & \multicolumn{2}{|c|}{ Microwave Disinfection } \\
\cline { 2 - 3 } & Non-Disinfected & Simulated \\
\hline \hline Canine & $0.15(0.01) \mathrm{a} \mathrm{A}$ & $0.16(0.01) \mathrm{a} \mathrm{A}$ \\
\hline First molar & $0.20(0.02) \mathrm{b} \mathrm{A}$ & $0.21(0.01) \mathrm{b} \mathrm{A}$ \\
\hline Posterior palate & $0.29(0.01) \mathrm{c} \mathrm{A}$ & $0.30(0.01) \mathrm{c} \mathrm{A}$ \\
\hline
\end{tabular}

Means values followed by different lower case letters in each column and upper case letters in each row differ significantly at $5 \%$.

Table 4 shows statistically significant difference $(p<.05)$ in the adaptation among regions for RSD method, when the denture bases were submitted to ND (canine: $0.11 \pm$ $0.01 \mathrm{~mm}$, first molar: $0.15 \pm 0.03 \mathrm{~mm}$, and posterior palate: 
$0.22 \pm 0.01 \mathrm{~mm}$ ) or RSD (canine: $0.12 \pm 0.01 \mathrm{~mm}$, first molar: $0.18 \pm 0.02 \mathrm{~mm}$, and posterior palate: $0.22 \pm 0.01 \mathrm{~mm}$ ) treatments. The best fit occurred in canine region, the worst was in posterior palate, and intermediary values were shown in first molar region. When the regions were compared individually, there was not statistically significant difference between the ND and RSD treatments ( $p>.05)$.

Table 4. Means Values (mm) for Denture Base Adaptation Concerning to Cut Region and Microwave Disinfection for RSFC Method (Standard Deviations are Given in Parenthesis)

\begin{tabular}{|c|c|c|}
\hline \multirow{2}{*}{ Region } & \multicolumn{2}{|c|}{ Microwave Disinfection } \\
\cline { 2 - 3 } & Non-Disinfected & Simulated \\
\hline \hline Canine & $0.11(0.01) \mathrm{a} \mathrm{A}$ & $0.12(0.01) \mathrm{a} \mathrm{A}$ \\
\hline First molar & $0.15(0.03) \mathrm{b} \mathrm{A}$ & $0.18(0.02) \mathrm{b} \mathrm{A}$ \\
\hline Posterior palate & $0.22(0.01) \mathrm{c} \mathrm{A}$ & $0.22(0.01) \mathrm{c} \mathrm{A}$ \\
\hline
\end{tabular}

Means values followed by different lower case letters in each column and upper case letters in each row differ significantly at $5 \%$.

\section{DISCUSSION}

The purpose of this investigation was to evaluate and compare the influence of repeated simulated disinfections by microwave energy on the adaptation of the maxillary denture base, using the TFC and RSFC methods. In the present in vitro study, the research hypothesis that the adaptation of the denture base could be adversely affected by RSD was not supported by the data. Three-way ANOVA revealed significant difference in denture adaptation for the variables closure and regions. The interactions between the factors were not significant (Table 1).

Adaptation of the complete denture base may be affected by dimensional changes that may occur during or after base polymerization $[2,4,6,28]$. Linear shrinkage may also occur when the acrylic resin is polymerized by microwave irradiation, which is considered to be a dry heat polymerization method [1].

Improvement in the adaptation of the denture base showed in the TFC method using one only simulated disinfection by microwave was claimed to be related to the additional linear shrinkage that results from the residual polymerization of the acrylic resin [10]. Conversely, in the present study, RSD by microwave energy had no influence on the adaptation of the denture base using either TFC or RSFC methods, when compared to those values obtained in the ND conditions (Table 2).

Based on this study conditions, RSD by microwave irradiation did not cause any effect on the denture base adaptation in both TFC and RSFC methods. It is possible that the simulated microwave disinfection cycle used in this study had promoted different dimensional changes in the denture base, resulting in a stabilization of the base distortion. Probably, this base dimensional stability is due to balance of the shrinkage promoted by the microwave irradiation and stresses releasing during the water storage. In this case, the linear shrinkage due to residual polymerization was not sufficient to increase the adaptation level of the base in the ND conditions, as showed in earlier study [10]. However, the use of a microwave disinfection cycle with greater energy intensity and larger application time produced great discrepancy in the base adaptation to the stone cast [8]. Repeated microwave disinfections at $690 \mathrm{~W}$ for 6 minutes promoted harmful to the adaptation of the denture bases [11].

When the flask closure methods were considered (Table 2), the best base adaptation was observed with the RSFC method, with significantly different values when compared to the TFC method in both ND and RSD conditions. Studies reporting the influence of different post-pressing times (immediate, 6, 12 and 24 hours) used before acrylic resin polymerization on base accuracy [6], as well as different flask closure pressures [28] have shown that adaptation improvement is also observed in denture bases prepared by the RSFC method when compared to those obtained by the TFC method.

RSD did not alter this finding, maintaining the denture base in better adaptation conditions, even when the flask closure was made with RSFC method. This result means that the denture base adaptation is not dependent of the flask closure method after RSD treatment, as well as it confirms that the dimensional change of the base probably occurs in the first simulated disinfection procedure [10]. In this present study, intermittent disinfections caused similar effects of shrinkage and expansion in the denture base, compensating the distortion effect occurred in the first SD procedure.

Despite the ability to produce a more accurate denture base in both ND and RSD procedures when compared to the TFC method, the RSFC method did not completely eliminate the dimensional changes that occurred during the denture base procedure.

When the region factor was analyzed in the TFC method (Table 3), there was significant difference in the adaptation values among the canine, first molar, and posterior palate region. The tendency for differences in accuracy between regions has also been shown in earlier studies investigating flask closure methods [28], commercial brands of acrylic resins [4], and effect of delay prior to acrylic resin polymerization [6] as a result of the maxillary anatomy [10].

Better base adaptation in the canine region may be due to association between anatomic condition of the anterior region and acrylic resin polymerization shrinkage, where the stress released does not cause significant base distortion. In contrast, the anatomy of the posterior palate region allowed a large base distortion, causing greater base inaccuracy, whereas the first molar region shows intermediate dimensional change. Conversely, despite the linear shrinkage of the acrylic resin to cause significant effect on the base adaptation, and the internal stress release to produce dimensional changes in the acrylic resin [1], there was not statistically significant difference in each region, when the ND and RSD conditions were compared.

Similar results for TFC method were obtained in the RSFC method (Table 4). These findings seem to confirm the different levels of the denture base adaptation in relation to different regions, independently of the studied variables. This fact shows the influence of the RSFC method in reduc- 
ing the level of the base inaccuracy, which was not modified by the RSD procedure.

The present study did not show statistically significant difference on the base adaptation under RSD effect by microwave energy, when 5 repeated disinfections at $650 \mathrm{~W}$ for 3 minutes were made with 24 hours interval and water storage at $37^{\circ} \mathrm{C}$ during the intervals. Probably, the water immersion time was sufficient to compensate the dimensional change occurred during the first disinfection, showing conflicting results when compared to previous work using $690 \mathrm{~W}$ for 6 minutes, and water storage for 7days between two disinfection procedures [9]. Probably, the conflicting findings are due to difference in the water storage period and/or potency and time of the microwave irradiancy used in the two studies.

The results of this study may be of clinical relevance when the denture bases were submitted to repeated microwave disinfection procedure as a clinic routine. On other hand, despite of this inaccuracy decrease between acrylic base and stone cast made by the RSFC method, the base adaptation remains still an inherent factor of the denture processing.

Although attempts were made to characterize the effect of RSD on denture base adaptation, this in vitro study is limited in predicting the effect of different microwave disinfection cycles. Further investigations are necessary to evaluate the effect of RSD on the denture adaptation in clinical use. Considering that the simulated microwave disinfection decreases the impact strength of the tooth/resin adhesion [29], and the effect on porosity appears only on the $2 \mathrm{~mm}$ thickness specimens [30], further studies are also necessary to verify the adhesion strength of the tooth-resin joint associate to mechanical retention of the tooth, commercial brands of acrylic resins, polymerization cycles, and denture base thickness.

\section{CONCLUSION}

Within the limitations of this study, the following conclusions were drawn:

1. RSD did not significantly affect the base adaptation in the TFC and RSFC methods. In ND and RSD conditions, the base adaptation performed in the RSFC methods was significantly better when compared to the TFC.

2. In the TFC and RSFC methods, the base adaptation was significantly different among regions in either ND or RSD conditions. In each region, the base adaptation performed in the TFC and RSFC methods was statistically similar when the ND and RSD conditions were compared.

\section{ACKNOWLEDGMENTS}

This study was supported by CNPq/PIBIC/UNICAMP at Piracicaba Dental School, State University of Campinas.

\section{REFERENCES}

[1] Anusavice KJ. Phillip's science of dental materials. 11th ed. St. Louis: Elsevier; 2003.

[2] Jackson AD, Grisius RJ, Fenster RK, Lang BR. The dimensional accuracy of two denture bases processing methods. Int J Prosthodont 1989; 2 (5):421-8.
[3] Sykora O, Sutow EJ. Posterior palatal seal adaptation: influence of processing technique, palate shape and immersion. J Oral Rehabil 1993; 20(1): 19-31.

[4] Consani RLX, Domitti SS, Rizzatti-Barbosa CM, Consani S. Effect of commercial types of acrylic resin on dimensional accuracy of denture base. Braz Dent J 2002; 13(1): 57-60.

[5] Consani RLX, Domitti SS, Mesquita MF, Correr-Sobrinho L. Dimensional stability of maxillary denture bases flasked with the RS tension system. Braz J Oral Sci 2003; 2(4):152-5.

[6] Consani RLX, Domitti SS, Mesquita MF, Consani S. Effect of packing types on the dimensional accuracy of denture base resin cured by conventional cycle in relation to post-pressing times. Braz Dent J 2004;15(1): 63-7.

[7] Shen C, Javid NS, Colaizzi FA. The effect of glutaraldehyde base disinfectants on denture base resins. J Prosthet Dent 1989; 61(5): 583-9.

[8] Pavan S, Arioli-Filho JN, Santos PH, Mollo FA. Effect of microwave treatments on dimensional accuracy of maxillary acrylic resin denture base. Braz Dent J 2005; 16(2): 119-23.

[9] Sartori EA, Schmidt CB, Walber LF, Shinkai RSA. Effect of microwave disinfection on denture base adaptation and resin surface roughness. Braz Dent J 2006; 17(3): 195-200.

[10] Consani S, Mesquita MF, Nobilo MAA, Henriques GEP. Influence of simulated microwave disinfection on complete denture base adaptation using different flask closure methods. J Prosthet Dent 2007; 97(3): 173-8.

[11] Fleck G, Ferneda F, Ferreira da Silva DF, Mota EG, Shinkai RS. Effect of two microwave disinfection protocols on adaptation of poly (methyl methacrylate) denture bases. Minerva Stomatol 2007; 56(3):121-7.

[12] Powell GL, Runnells RD, Saxon BA, Whisenant BK. The presence and identification of organisms transmitted to dental laboratories. J Prosthet Dent 1990; 64(2): 235-7.

[13] Katberg JW. Cross-contamination via the prosthodontic laboratory. J Prosthet Dent 1974; 32 (4): 412-9.

[14] Kahn RC, Lancaster MV, Kate W, Jr. The microbiologic crosscontamination of dental prostheses. J Prosthet Dent 1982; 47(5): $556-9$.

[15] Verran J, Kossar S, McCord JF. Microbiological study of selected risk areas in dental technology laboratories. J Dent 1996; 24 (12):77-80.

[16] Rudd RW, Senia ES, McCleskey FK, Adams ED. Sterilization of complete dentures with sodium hypochlorite. J Prosthet Dent 1984; 51(3): 318-21.

[17] Henderson CW, Schwarz RS, Herbold ET, Mayhew RB. Evaluation of the barrier system, an infection control system for the dental laboratory. J Prosthet Dent 1987; 58(4): 517-21.

[18] Shen C, Javid NS, Colaizzi FA. The effect of glutaraldehyde base disinfectants on denture base resins. J Prosthet Dent 1989; 61 (5): 583-9.

[19] Bell JA, Brockmann SL, Feil P, Sackuwick DA. The effectiveness of two disinfectants on denture base acrylic resin with an organized load. J Prosthet Dent 1989; 61(5): 580-3.

[20] Brace ML, Plummer KD. Practical denture disinfection. J Prosthet Dent 1993; 70(6): 538-40.

[21] Chau VB, Saunder TR, Pimsler M, Elfring DR. In-depth disinfection of acrylic resins. J Prosthet Dent 1995; 74(3): 309-13.

[22] Rohrer MD, Bulard RA. Microwave sterilization. J Am Dent Assoc 1985; 110(2): 194-8.

[23] Baysan A, Wiley R, Wright PS. Use of microwave energy to disinfect a long-term soft lining material contaminated with Candida albicans or Staphylococcus aureus. J Prosthet Dent 1998; 79(4): 4548.

[24] De Clerk JP. Microwave polymerization of acrylic resins used in dental prostheses. J Prosthet Dent 1987; 57(5): 650-8.

[25] Polyzois GL, Zissis AJ, Yannikakis SA. The effect of glutaraldehyde and microwave disinfection on some properties of acrylic denture resin. Int J Prosthodont 1995; 8(2):150-4.

[26] Thomas CJ, Webb BC. Microwaving of acrylic resin dentures. Eur J Prosthodont Res Dent 1995; 3(4): 179-82.

[27] Anthony DH, Peyton FA. Evaluating dimensional accuracy of denture bases with a modified comparator. J Prosthet Dent 1959; 9(4): 683-92.

[28] Consani RLX, Domitti SS, Consani S. Effect of a new tension system used in acrylic resin flasking on the dimensional stability of maxillary denture bases. J Prosthet Dent 2002; 88(3): 285-9. 
[29] Consani RLX, Mesquita MF, Zampieri MH, Mendes WB, Consani $\mathrm{S}$. Effect of the simulated disinfection by microwave energy on the impact strength of the tooth/acrylic resin adhesion. Open Dent J 2008; 2: 13-7.

Received: February 26, 2008

Revised: March 27, 2008

(c) Consani et al.; Licensee Bentham Open.

This is an open access article distributed under the terms of the Creative Commons Attribution License (http://creativecommons.org/licenses/by/2.5/), which permits unrestrictive use, distribution, and reproduction in any medium, provided the original work is properly cited.
[30] Pero AC, Barbosa DB, Marra J, Ruvolo-Filho AC, Compagnoni MA. Influence of microwave polymerization method and thickness on porosity of acrylic resin. J Prosthodont 2008; 17: 125-9. 